\title{
Key hormonal and metabolic control systems modifying nutrient use
}

\section{By T. E. C. WeEkes, Department of Agricultural Biochemistry and Nutrition, University of Newcastle upon Tyne, Newcastle upon Tyne $N E$ I ${ }_{7} R U$}

This review focuses on the mechanisms by which the neuro-endocrine environment of a ruminant animal participates in the control of nutrient use. Examples of the regulation of ruminant carbohydrate metabolism are used to illustrate the type of information required to obtain a quantitative description of endocrine control of metabolism. Finally, attention is directed to an example of a metabolic response, that to exercise, in which a quantitative analysis of hormone actions will be of value.

\section{Metabolic pathways}

Metabolic pathways have traditionally been treated as a series of enzyme-catalysed chemical reactions taking place within a specific tissue. The majority of such pathways involved in the metabolism of absorbed nutrients, energy provision and energy storage have apparently been identified and partially characterized in ruminant tissues. Some uncertainties remain, for instance the pathway of ketogenesis in the rumen epithelium (Emmanuel et al. 1982), but interest is increasingly directed to quantitative measurements of flux through the pathways and their control. To understand the way in which nutrients are partitioned between competing anabolic and catabolic processes, a wider concept of a metabolic pathway is required, starting from either absorption of a nutrient input or nutrient mobilization from a tissue store. Following transport through the blood stream, nutrients are taken up and metabolized by one or more tissues before finally being excreted or deposited in a storage form. Within such an extended metabolic pathway, flux may be regulated by extracellular neuro-endocrine control of tissue blood flow and nutrient transport as well as by intracellular acute regulation of enzyme activities by substrates, products and allosteric effectors and chronic regulation of enzyme amount and the ability of the tissue to respond to acute regulation.

Recent theories of metabolic regulation propounded by Kacser \& Burns (1979) suggest that flux through a metabolic pathway is not wholly controlled by a single 'rate-limiting' step but rather that control is shared to varying degrees by all steps in a pathway. The size of the control coefficient for an individual reaction depends on the environment of the whole pathway, rather than being a fixed property of an individual enzyme. This concept has been used to study the control of mitochondrial respiration (Groen et al. 1982) and may prove useful in understanding regulation of ruminant metabolism in the future, although theoretical difficulties do exist with this approach (Crabtree \& Newsholme, 1985). 
An alternative to calculation of control coefficients is to construct a mathematical model describing metabolism either in the whole animal (Gill et al. 1984 ) or in an individual tissue, for which fluxes through each enzyme reaction can be calculated (Baldwin et al. 1976; Waghorn \& Baldwin, 1984). Endocrine effects on tissue metabolism can be included in the model (Baldwin et al. 1976) or separate models can be constructed, as in the case of control and glucagon-treated rat hepatocytes (Rabkin \& Blum, r 985 ). A quantitative description of the endocrine control of metabolism requires an understanding of the mechanisms by which the hormonal environment controls flux through competing metabolic pathways.

\section{Hormonal co-ordination of metabolism}

The metabolic state of an animal depends on the co-ordinated balance between the nervous and endocrine systems partitioning substrates between competing anabolic and catabolic pathways. Hormone secretion depends on the availability of specific nutrients modulated by neural and hypothalamic control mechanisms, while nutritional status also modulates nervous activity (Landsberg \& Young, 1983). Neurohormonal responses are further influenced by the external environment, including such factors as environmental temperature and stress and by the physiological status of the animal, including age, stage of development and reproductive status. Bauman \& Currie (1980) suggested that hormonal regulation can be classified into homeostatic control, directed at maintaining a constant internal environment, and homeorhetic control, defined as the co-ordinated control of metabolism in support of a dominant physiological process, such as growth or lactation. The same hormones can be involved in both homeostatic and homeorhetic regulation. The involvement of insulin in the maintenance of glucose homeostasis is well known (McDowell, 1983), the hormone acting in concert with glucagon, catecholamines and the sympathetic nervous system. Homeorhetic changes in adipose tissue metabolism during pregnancy and lactation involve changes in the ability of insulin to stimulate lipogenesis and inhibit lipolysis, mediated by progesterone, prolactin and growth hormone modifying either the numbers of insulin receptors present or the responsiveness of intracellular metabolism to insulin (Vernon \& Flint, 1983 ). Similarly changes in the proportions of protein and fat deposited during growth in ruminants may reflect changes in the relative ability of insulin to stimulate net protein and fat deposition, under homeorhetic regulation by changing growth hormone and cortisol secretion (Weekes, I 986). The function of the growth hormone-insulin-like growth factor (IGF) axis in the control of growth is subject to homeorhetic regulation by insulin, thyroid hormones, cortisol, androgens and oestrogens, which determine the ability of growth hormone to stimulate IGF production and the ability of IGF to stimulate growth (Spencer, 1985). Growth hormone secretion is itself subject to hypothalamic regulation by growth-hormone-releasing factor and somatostatin; the relative secretion of these peptides may allow integration of neural inputs controlling the normal pulsatile release of growth hormone and homeorhetic regulation of growth hormone secretion during lactation and growth. A 
homeorhetic function for somatostatin is supported by increased growth rates in lambs immunized against somatostatin (Spencer et al. 1983).

The hypothesis that metabolism is subject to homeostatic and homeorhetic neuro-endocrine control provides a valuable conceptual framework but does not in itself allow quantitative determination of hormonal effects of metabolism. To reach this level we need to consider the mechanism of hormonal action in more detail.

\section{Mechanism of hormonal action}

Many reports assume either explicitly or more commonly implicitly that metabolic responses to hormones are directly proportional to plasma hormone concentrations. This hypothesis is adequate in some situations, for instance elevated glucogen levels in exercising sheep directly stimulate increased hepatic glucose production, at least in the early stages of exercise (Brockman \& Halvorson, 1981). In other situations such an assumption may be misleading. Chronic cold exposure reduces insulin secretion in sheep in response to a variety of stimuli (Sasaki et al. 1982), yet the responsiveness of glucose metabolism to a given level of insulin is increased during cold exposure (Weekes et al. 1983). Consideration must therefore be given to both the regulation of plasma hormone concentrations and the ability of a circulating hormone to influence tissue metabolism.

The effective circulating level of a hormone depends on the rate of hormone secretion in response to stimulatory or inhibitory neural, hormonal and chemical signals, the extent of hormone binding to plasma proteins and the rate of hormone degradation. The relative importance of neural and metabolic signals in the control of insulin secretion has been determined quantitatively for the rat (Berthoud, 1984) and although a quantitative description is lacking, the signals stimulating insulin secretion in ruminants are well characterized. Changes in hormone degradation may also be of significance. Thus in growing lambs fed at a fixed level per unit metabolic body-weight, the metabolic clearance rate of insulin decreased with body-weight in the range $30-42 \mathrm{~kg}$ (T. E. C. Weekes and C. M. Watson, unpublished observations). The increasing plasma insulin response to feeding observed previously in lambs over a similar range of body-weight (Godden \& Weekes, 198I) may therefore at least partially reflect changes in insulin metabolism rather than an increase in insulin secretion.

Changes in the ability of circulating hormones to influence tissue metabolism are less-well characterized in ruminants than are changes in hormone concentrations. The ability of a hormone to regulate metabolic flux depends first on the rate of delivery of the hormone to the target organ. Regulation at this level, by changes in organ blood flow, may occur in adipose tissues after feeding (Barnes et al. r983), but is a relatively non-specific mechanism, in that the supply of all blood-borne nutrients and hormones will be affected. On arrival at the target organ, the hormone binds to a specific receptor, located on the plasma membrane in the case of peptide hormones. Binding to the receptor results in generation of a signal, such as $3^{\prime}, 5^{\prime}$-cyclic AMP for glucagon, or activation of a receptor tyrosine kinase for insulin (Fain, 1984), which produces the ultimate biological response of changes in 
the activity or amount of enzyme or transport proteins in the cell. Numerous examples have been documented for non-ruminant animals of neural, hormonal and nutritional regulation of either the number or affinity of hormone receptors or of the responsiveness of post-receptor events to hormone action. Regulation at either the receptor or post-receptor level can be detected by a change in the shape of the sigmoid hormone dose-response curve (Weekes, 1983). The shape of this curve can be described mathematically by a four parameter logistic equation (De Lean et al. 1978):

$$
y=\frac{a-d}{1+(x / c)^{b}}+d
$$

where $x$ represents the dose (plasma hormone concentration) and $y$ represents the biological response measured. The four fitted parameters represent respectively: $a$, response at zero dose; $b$, slope factor; $c$, hormone concentration for $50 \%$ of maximal response; $d$, response at maximal dose. Calculation of hormone responses in terms of eqn ( $\mathrm{I}$ ) allows the hormonal regulation of tissue metabolism to be described quantitatively. Recent studies of insulin actions in sheep are presented below to illustrate the approach.

\section{Sensitivity and responsiveness of glucose metabolism to insulin}

Of the four parameters given previously, the most commonly measured are $c$ and $d$, which represent the sensitivity of the response to the hormone and the maximum responsiveness to the hormone respectively. In a system with spare hormone receptors, changes in sensitivity alone will generally reflect changes in the number or affinity of tissue hormone receptors, while changes in responsiveness with no change in sensitivity indicate an effect at a post-receptor level. We have investigated the influence of cold exposure (Weekes et al. 1983), diet (Janes et al. 1985), growth and exogenous thyroxine treatment (Table I) on the sensitivity and responsiveness of body glucose metabolism (expressed as the glucose metabolic clearance rate) to insulin in sheep, using the euglycaemic insulin clamp procedure (Weekes et al. 1983). Table I also includes effects of insulin on endogenous gluconeogenesis and on plasma metabolite levels. In the latter case, metabolite kinetics should be measured before results can be strictly compared with effects on body glucose kinetics. Table I demonstrates that metabolic pathways differ in their sensitivity and responsiveness to insulin, with the reduction in plasma glycerol being particularly sensitive, as is the inhibition of lipolysis in non-ruminants (Hom \& Goodner, 1984). Chronic thyroxine treatment did not significantly affect the responsiveness of glucose metabolism to insulin, but the sensitivity of glucose utilization to insulin was increased, suggesting an increased insulin receptor number or affinity on target tissues, predominantly skeletal muscle.

The effect of an exogenous supply of glucose on insulin action was studied using the same technique in sheep receiving diets of dried grass or a pelleted 


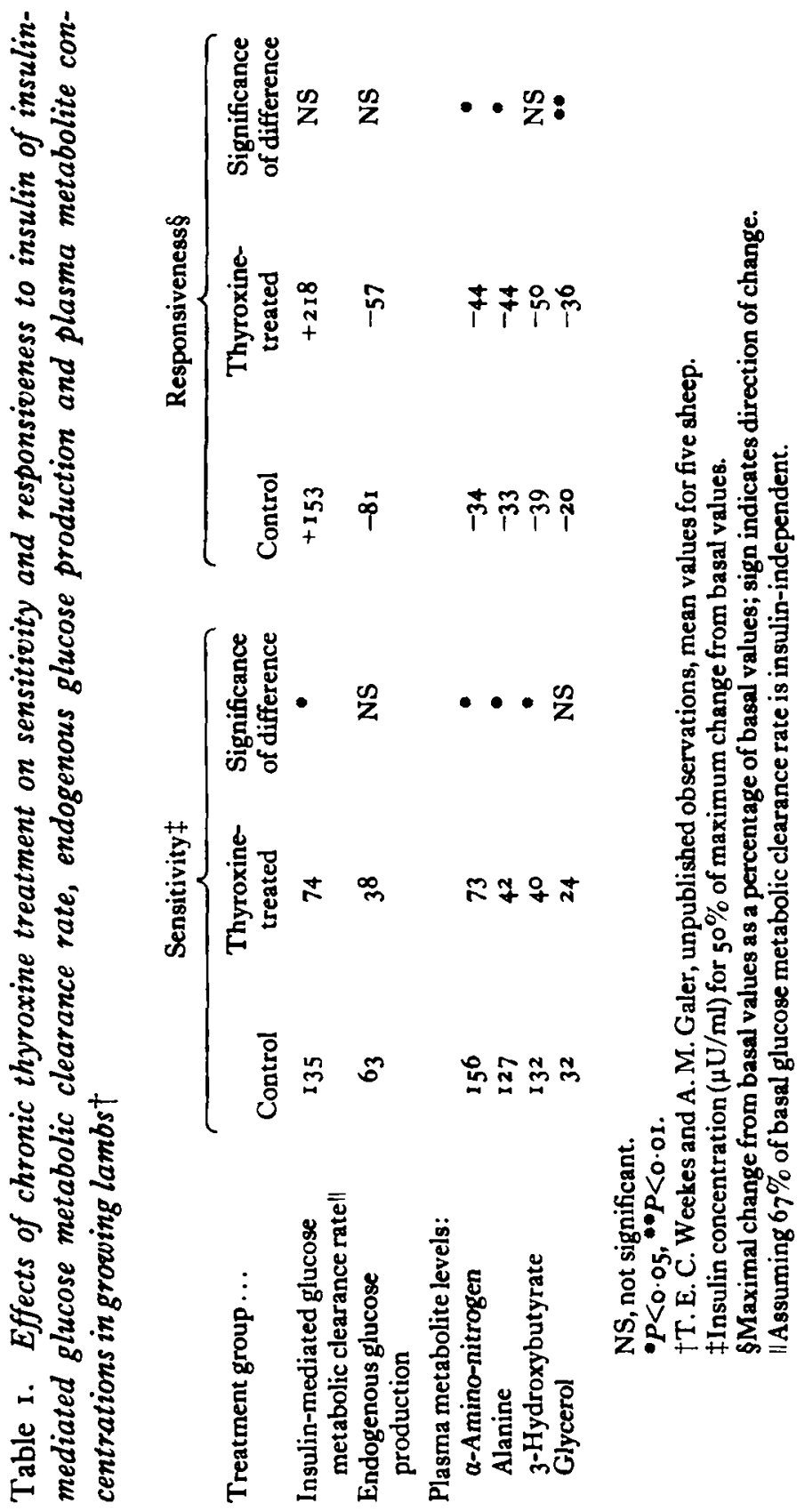


ground-maize-based concentrate (Janes et al. 1985). Total rates of glucose absorption into the mesenteric venous blood were 7 and $101 \mathrm{~g} / 24 \mathrm{~h}$ for the grass and maize diets respectively. Diet had no effect on the sensitivity or responsiveness of glucose metabolism to insulin. However, the calculated rate of glucose metabolism at zero insulin concentration (parameter $a$ in eqn (I)), representing the rate of glucose metabolism that was independent of insulin, was significantly elevated when the maize diet was given. Insulin-independent glucose metabolism in man is largely accounted for by brain glucose utilization (Gottesman et al. 1983), but known rates of glucose uptake by the entire central nervous system of sheep can only account for $8-14 \%$ of the rate of insulin-independent glucose utilization. Thus our analysis predicts that in sheep a large proportion of insulin-independent glucose uptake occurs in other tissues, most likely in the splanchnic bed (Janes et al. 1985 ). This illustrates the way in which a quantitative analysis of hormonal regulation can highlight deficiencies in our knowlege of ruminant biochemistry.

\section{Responses to exercise in ruminants}

The metabolic and hormonal responses to exercise in sheep provides an example of the potential application of the techniques described previously. Exercise at an intensity sufficient to increase body energy expenditure threefold resulted in a fivefold increase in hind-limb blood flow, with increased arterial concentrations of free fatty acids (FFA), glucose and lactate, indicating an increased rate of lipolysis in adipose tissue and gluconeogenesis in the liver (Bird et al. 1981). Hind-limb FFA uptake was dramatically increased and glucose uptake increased two- to fourfold, although the glucose arteriovenous difference was unchanged by exercise. Endocrine responses to exercise are consistent with the metabolic responses in that glucagon, cortisol and catecholamine levels are elevated by exercise of a similar intensity, which will serve to stimulate lipolysis and gluconeogenesis (Brockman, r 982; Bell et al. 1983). Plasma insulin levels decline, at least in strenuous exercise (Brockman, 1979), which would serve to reduce this hormone's inhibitory effects on lipolysis and gluconeogenesis. At the same time, however, a lower plasma insulin and an elevated cortisol level might reduce hind-limb glucose extraction, a process which is stimulated by insulin in ruminants (Prior et al. 1984). An acute bout of exercise in untrained human subjects increases insulin binding to receptors (Koivisto et al. 1980). A similar increase in sensitivity to insulin in exercising sheep, coupled with increased hind-limb blood flow, may allow muscle glucose uptake to be maintained in the face of hypoinsulinaemia. A quantitative examination of hind-limb responses to insulin would test this hypothesis. A similar study may be valuable in exercise-trained ruminants, since training increases sensitivity to insulin in rats (James et al. 1984) and man (Sato et al. 1984). The possibility therefore exists that ruminants kept in an outdoor environment are more sensitive to insulin than are housed animals used for most studies of metabolic regulation. 
This example illustrates the way in which studies of tissue responses to a hormone can be combined with measurements of hormone secretion to provide quantitative values for the endocrine regulation of nutrient use in ruminants, which will be of value in refining mathematical descriptions of ruminant metabolism (Gill et al. 1984).

Financial support from the Agricultural and Food Research Council and the Ministry of Agriculture, Fisheries and Food is gratefully acknowleged.

\section{REFERENCES}

Baldwin, R. L., Yang, Y. T., Crist, K. \& Grichting, G. (1976). Federation Proceedings 35, $2314-2318$.

Barnes, R. J., Comline, R. S. \& Dobson, A. (1983). Quarterly foumal of Experimental Physiology 68, $77-88$.

Bauman, D. E. \& Currie, W. B. (1980). Fournal of Dairy Science 63, 1514-1529.

Bell, A. W., Bassett, J. M., Chandler, K. D. \& Boston, R. C. ( $(983)$. Fournal of Developmental Biology 5, 129-141.

Berthoud, H. R. (1984). Metabolism 33, 18-25.

Bird, A. R., Chandler, K. D. \& Bell, A. W. ( 1981 ). Australian fournal of Biological Sciences 34, $54^{1-55^{\circ}}$.

Brockman, R. P. (1979). Australian fournal of Biological Sciences 32, $215-220$.

Brockman, R. P. (1982). Canadian Foumal of Physiology and Pharmacology 60, 1459-1463.

Brockman, R. P. \& Halvorson, R. (1981). Australian Yournal of Biological Sciences 34, 551-560.

Crabtree, B. \& Newsholme, E. A. (1985). Trends in Biochemical Sciences 10, 188.

De Lean, A., Munson, P. J. \& Rodbard, D. (1978). American Fournal of Physiology 235, E97-E102.

Emmanuel, B., Stangassinger, M. \& Giesecke, D. (1982). Comparative Biochemistry and Physiology 72B, 415-419.

Fain, J. N. (1984). Metabolism 33, 672-679.

Gill, M., Thornley, J. H. M., Black, J. L., Oldham, J. D. \& Beever, D. E. (1984). British Fournal of Nutrition 52, 621-649.

Godden, P. M. M. \& Weekes, T. E. C. (198I). Foumal of Agricultural Science, Cambridge 96, $353-362$.

Gottesman, I., Mandarino, L. \& Gerich, J. (1983). American Foumal of Physiology 244, E632-E635.

Groen, A. K., Wanders, R. J. A., Westerhoff, H. V., van der Meer, R. \& Tager, J. M. (1982). Journal of Biological Chemistry 257, 2754-2757.

Hom, F. G. \& Goodner, C. J. (1984). Diabetes 33, $153-159$.

James, D. E., Kraegen, E. W. \& Chisholm, D. J. (1984). Fournal of Applied Physiology 56, $1217-1222$.

Janes, A. N., Weekes, T. E. C. \& Armstrong, D. G. (1985). British Youmal of Nutrition 54, 459-47I.

Kacser, H. \& Burns, J. A. (1979). Biochemical Society Transactions 7, I $149-1160$.

Koivisto, V., Soman, V., Nadel, E., Tamborlane, W. V. \& Felig, P. (I 980 ). Federation Proceedings $39,1481-1486$.

Landsberg, L. \& Young, J. B. (1983). American fournal of Clinical Nutrition 38, 1018-1024.

McDowell, G. H. (1983). Proceedings of the Nutrition Society 42, 149-167.

Prior, R. L., Huntington, G. B. \& Reynolds, P. J. (1984). fournal of Animal Science 58, $1446-1453$.

Rabkin, M. \& Blum, J. J. (1985). Biochemical fournal 225, 761 -786.

Sasaki, Y., Takahashi, H., Aso, H., Ohneda, A. \& Weekes, T. E. C. (Ig82). Endocrinology I I I, $2070-2076$. 
Sato, Y., Iguchi, A. \& Sakamoto, N. (1984). Hormone and Metabolic Research 16, 483-486.

Spencer, G. S. G. (1985). Livestock Production Science 12, 31-46.

Spencer, G. S. G., Garssen, G. J. \& Hart, I. C. (1983). Livestock Production Science 10, 25-37.

Vernon, R. G. \& Flint, D. J. (1983). Proceedings of the Nutrition Society 42, 315-331.

Waghorn, G. C. \& Baldwin, R. L. (1984). Fournal of Dairy Science 67, 531-544.

Weekes, T. E. C. (1983). Proceedings of the Nutrition Society 42, $129-136$.

Weekes, T. E. C. (1986). In Control and Manipulation of Animal Growth, [P. J. Buttery, N. B. Haynes and D. B. Lindsay, editors]. London: Butterworths (In the Press.)

Weekes. T. E. C., Sasaki, Y. \& Tsuda, T. (1983). American Fournal of Physiology 244, $\mathrm{E}_{335}-\mathrm{E}_{345}$. 